\title{
An Empirical Analysis of CAPM and Fama-French Three- Factor Model -- Based on the Example of Shanghai Stock Exchange
}

Ziyi Li

School of Economics, Sichuan University, Chengdu 610000, China

\begin{abstract}
Some scholars, represented by William F. Sharpe and John Lintner, have established the "Capital Asset Pricing Model" (CAPM) in the 1960s. This model finds that under certain assumptions the expected rate of return shows a clear linear relationship with market risk (systemic risk), no matter for a single asset or a combined asset. Capital Asset Pricing Model (CAPM), is regarded as the spine of modern price theory in financial market. It has been applied widely to asset pricing analysis and determination, such as stocks, funds and bonds and to investment decision field. This essay based on CSMAR data, separately uses CAPM and the FamaFrench Three-Factor Model to conduct empirical test on the expected return of SSE A-share portfolio. The main conclusion is that in China's stock market, market risk is not the only factor which determines the expected return of the market portfolio or individual stock, while the size factor (SMB) and book-to-market ratio factor (HML) can better explain the portfolio's expected rate of return.
\end{abstract}

Key words: CAPM; Fama-French Three-Factor Model; Shanghai Stock Exchange

Publication date: December, 2020

Publication online: 31 December, 2020

"Corresponding author: Ziyi Li, 1379185443@ qq.com

\section{Background introduction}

Modern invest theory has developed rapidly since the portfolio theory was proposed by Harry M.
Markowitz in 1952. And Capital Asset Pricing Model undoubtedly becomes the most core part of it. William F. Sharpe, John Lintner (1965) and Jan Mossin (1966) independently proposed the famous Capital Asset Pricing Model (CAPM). The model, which is based on the basic assumptions from Efficient Markets Hypothesis, assumes that all investors with the same expectation will choose a market portfolio to invest, and then will use the CAPM formula to measure the expected rate of return of a particular security.

The most famous example of how to select suitable factors is the Fama-French Three-Factor Model (1992). From the perspective of factors which can influence a company, the model takes the following three factors into consideration: market return rate or market index return rate, portfolio return of small stocks over large stocks, and portfolio return of high market ratio stocks over low market ratio stocks.

The factors that affect the return of stocks are diverse, due to the late development of China's security market. Therefore, it is not enough to interpret the return of stocks only by systemic risks. SMB and HML have a good explanatory effect on stock returns. Therefore, this essay conducts an empirical study based on the Chinese stock market after the financial crisis, and it examines how the CAPM and the Three-Factor Model explain stock returns at the same time. Through scientific comparison and analysis, the essay explores models suitable for China's market, in order to better explain and predict the rate of return and development trend of China's stock market in the future. 
2 Parameter estimation method for CAPM and Fama-French model

\subsection{Theoretical analysis of CAPM}

\subsubsection{Assumptions}

(1) All investors are risk-averse and rationally invest with maximum utility.

(2) All investors can accept all price in a fully competitive market.

(3) Market Efficiency Hypothesis (EHM), which means the market is fully effective. In such a market, investors have unblocked information without any cost, and have the same expectation for the market with a similar analysis and no transaction cost.

\subsubsection{Basic form}

The expected return of stocks in CAPM can be shown as follows:

$$
E\left(R_{i}\right)-R_{f}=\beta_{i}\left[E\left(R_{M}-R_{f}\right)\right]
$$

In this formula, RM is the rate of return of all stock portfolios in the market, $\mathrm{Rf}$ is the risk-free return rate, $\mathrm{Ri}$ is the rate of return of type i stock, and the systemic risk of type i stock relative to all stock portfolios I in the market is

$$
\beta \frac{\operatorname{Cov}\left(R_{i}, R_{M}\right)}{\operatorname{Var}\left(R_{M}\right)}
$$

But the stock portfolio $\mathrm{M}$ is difficult to obtain, so we need to use an appropriate portfolio I to replace it. The research shows that when the number of stocks in portfolio I reaches about $30, \sigma^{2} i$ is very close to $\sigma_{M}^{2}$. Therefore, $\beta \mathrm{M}$ can be replaced by systemic risk $\beta \mathrm{i}$ of type i stock relative to stock portfolio I.

The formula is expressed as follows: $\mathrm{R}_{\mathrm{i}}$ $\mathrm{R}_{\mathrm{f}}=\alpha_{\mathrm{i}}+\beta_{\mathrm{i}}\left(\mathrm{R}_{\mathrm{M}}-\mathrm{R}_{\mathrm{f}}\right)+\varepsilon_{\mathrm{i}}$

The inspection form is as follows: $R_{i}=\alpha_{i}+\beta_{i} R_{M}+\varepsilon_{i}$

In it: $\mathrm{R}_{\mathrm{i}}=\mathrm{E}\left(\mathrm{R}_{\mathrm{i}}\right)-\mathrm{R}_{\mathrm{f}} \quad \mathrm{R}_{\mathrm{M}}=\mathrm{E}\left(\mathrm{R}_{\mathrm{M}}\right)-\mathrm{R}_{\mathrm{f}}$

\subsubsection{Theoretical connotation}

According to CAPM, the necessary rate of return required by an asset depends on three factors:

(1) Risk-free rate of return, that is, bank deposit (or treasury bond) is regarded as risk-free investment.

(2) The expected rate of return of the market, which is the expected rate of return of the whole market. If the risk of an asset is the same as the expected risk of the market, the return rate of it is the same as that of the whole market;

(3) The systemic risk coefficient of asset portfolio, namely $\beta$ coefficient. It is the ratio of the risk degree of a certain asset portfolio to that of the market portfolio.

If $\beta>1$, the risk of the portfolio is greater than the market risk, and the required return on assets should more than the expected return rate of the market. The excess part becomes the risk premium, which is the compensation for the part of the risk that exceeds the market risk.

The main result of CAPM illustrates that the relationship between expected return rate of single asset or portfolio and the relative risk degree. The higher the risk degree of any asset relative to the whole market portfolio, the higher compensation it needs.

\subsection{Fama-French Three Factor Model (TFM)}

\subsubsection{Assumptions}

The hypothesis of Fama-French Three Factor Model includes two parts: theoretical hypothesis and statistical hypothesis.

Theoretical hypothesis:

(1) There are many investors.

(2) All investors plan their investment portfolio in the same stock.

(3) The investment scope is limited to assets traded in the open financial market.

(4) There is no stock transaction fee (Commission and service fee, etc.) and tax.

(5) Investors have the same expectation for the mean, variance and covariance of the return rate.

(6) All investors have the same opinion about the stock and the economic situation.

Statistical hypothesis:

(1) $\left(\mathrm{R}_{\mathrm{M}}-\mathrm{R}_{\mathrm{F}}\right)$, SMB and HML are not correlated with random error term $\xi$.

(2) $\mathrm{E}(\xi \mathrm{i})=0$

(3) It is assumed that the variance of $\xi$ is a constant;

(4) $\operatorname{COV}=(\xi \mathrm{i}, \xi \mathrm{j})=0, \mathrm{i} \neq \mathrm{j}$, that is, there is no linear correlation between the explanatory variables, in other words, there is no exact linear relationship between the two explanatory variables.

(5) It is assumed that the random error term $\xi$ obeys the normal distribution of which mean value is 0 and variance is $\mathrm{S} 2$, that is, $\xi \mathrm{i} \sim \mathrm{N}(0, \mathrm{~S} 2)$

\subsubsection{Model representation}

Based on the CAPM model, Fama-French model adds two new factors: the company scale factor (SMB) 
and the book market factor (HML)

The model is shown as follows: $E\left(R_{i}\right)-R_{j}=b_{i}\left[E\left(R_{M}-R_{f}\right)\right]+s_{i} E(S M B)+h_{i} E(H M L)$

In it, SMB is the expected market risk premium for the scale of the company issuing shares, that is, the yield of small-scale stock portfolio minus the yield of large-scale stock portfolio.

HML is the risk premium of book market factor, that is, the yield of high market value stock portfolio minus the yield of low market value stock portfolio. The inspection form is as follows:

$$
R_{i u}=\alpha_{i}+b_{i} R_{M t}+s_{i} E\left(S M B_{t}\right)+h_{i} E H M L+\varepsilon_{t}
$$

In this form,

$$
R_{i}=E\left(R_{i}\right)-R_{f} \quad R_{M}=E\left(R_{M}\right)-R_{f}
$$

\section{Empirical analysis of CAPM and Fama- French model}

\subsection{Data selection}

I choose the monthly data of Shanghai Stock
Exchange in 2010 for empirical research, aiming to analyze whether the Three Factor Model can still explain the return rate of China's stock market after the financial crisis. All the data are selected from CSMAR database, and all stocks are SSE A-share.

According to Fama's paper published in 1993, different with the general non-financial listed companies, financial companies have high leverage ratio, because non-financial companies with high leverage will take a lot of risks.

Among them, the risk-free rate of return is the monthly interest rate of one-year demand deposit interest rate.

The market portfolio rate of return is the monthly rate of return of Shanghai Stock Exchange.

The scale is expressed in total market value.

The book to market ratio is calculated by net assets and price of per share.

\subsection{CAPM}

Table 1. CAPM result

\begin{tabular}{ccccccc}
\hline $\mathbf{R}^{2}$ & $\boldsymbol{\alpha i}$ & $\mathbf{t}$ & $\boldsymbol{\beta i}$ & $\mathbf{t}$ & $\mathbf{D M}$ & $\mathbf{P}-\mathbf{v a l u e}$ \\
0.835701 & 0.016780 & 1.755769 & 0.983786 & 7.131933 & 1.838859 & 0.000032 \\
\hline
\end{tabular}

According to the above table 1 , the value estimated by CAPM is 0.835 , which is an acceptable result. However, when it comes to each stock, CAPM does not explain the yield very well. It shows that systematic risk $\beta$ is insufficient to explain the yield level of each stock, because the proportion of systemic risk in the total risk is not large, and there are other factors that affect the stock return.

\subsection{The Three Factor Model}

\subsubsection{Factor construction}

First, I form six combinations according to the ratio of the company's market value to book value; then I use these six combinations to simulate the yield of "scale factor" and "value factor". The specific steps are as follows:

First step, to sort all the stocks in the sample according to their market value at the end of December each year. The stocks in the sample are divided into two groups by the median of the total market value, namely the small group (S) and the large group (B). They are also sorted according to the book to market ratio, with the cutoff point minimum $30 \%(\mathrm{~L})$, the middle $40 \%(\mathrm{M})$ and the maximum $30 \%(\mathrm{H})$ (if they are sorted according to the price to book ratio, the order is just the opposite). In this way, we can construct six combinations by the above two classification methods, and calculate the return of six combinations with equal weight

Secondly, calculate the SMB and HML by using the six combinations that have been constructed. The calculation method is as follows

$$
\begin{gathered}
S M B=\left(\frac{S / L+S / M+S / H}{3}\right)-\left(\frac{B / L+B / M+B / H}{3}\right) \\
H M L=\left(\frac{S / H+B / H}{2}\right)-\left(\frac{S / L+B / L}{2}\right)
\end{gathered}
$$

\subsubsection{Empirical results of the model}


Table 2. Factor monthly data (yield)

\begin{tabular}{|c|c|c|c|c|c|c|c|c|c|}
\hline Date & $\mathbf{S} / \mathbf{H}$ & $\mathbf{S} / \mathbf{M}$ & $\mathbf{S} / \mathbf{L}$ & $\mathrm{B} / \mathrm{L}$ & B/M & $\mathbf{B} / \mathbf{H}$ & HML & SMB & Rm-Rf \\
\hline 2010.1 & -0.04585 & -0.0216 & -0.03 & -0.015 & -0.0134 & -0.08 & -0.04 & 0.005 & -0.0903 \\
\hline 2010.2 & 0.078288 & 0.07671 & 0.083 & 0.0487 & 0.04743 & 0.04 & -0.01 & 0.034 & 0.01888 \\
\hline 2010.3 & 0.029941 & 0.04364 & 0.064 & 0.0238 & 0.02163 & 0.013 & -0.02 & 0.026 & 0.01748 \\
\hline 2010.4 & -0.11713 & -0.0748 & -0.07 & 0.0094 & -0.0478 & -0.11 & -0.08 & -0.04 & -0.0782 \\
\hline 2010.5 & -0.11157 & -0.1069 & -0.1 & -0.03 & -0.0937 & -0.12 & -0.05 & -0.02 & -0.0955 \\
\hline 2010.6 & -0.09629 & -0.1173 & -0.09 & -0.1 & -0.1071 & -0.08 & 0.01 & -0.01 & -0.0711 \\
\hline 2010.8 & 0.058122 & 0.10763 & 0.105 & 0.1254 & 0.08215 & 0.012 & -0.08 & 0.017 & -0.002 \\
\hline 2010.9 & -0.00326 & 0.01619 & 0.025 & 0.0839 & 0.04068 & -0.01 & -0.06 & -0.03 & 0.00667 \\
\hline 2010.10 & 0.049522 & 0.06862 & 0.053 & 0.1205 & 0.13359 & 0.117 & -0 & -0.07 & 0.12066 \\
\hline 2010.11 & -0.0244 & 0.00753 & 0.018 & 0.0487 & -0.0094 & -0.07 & -0.08 & 0.01 & -0.0561 \\
\hline 2010.12 & -0.03432 & -0.0261 & -0.02 & -0.006 & -0.0121 & -0.02 & -0.01 & -0.01 & -0.0063 \\
\hline
\end{tabular}

Table 3. Least squares regression of Three factor model

\begin{tabular}{|c|c|c|c|c|c|c|}
\hline Combinations & $\alpha \mathbf{i}$ & $\beta \mathbf{i}$ & si & hi & $\mathbf{R}^{2}$ & P-value \\
\hline $\mathrm{S} / \mathrm{H}$ & $2.66 \mathrm{E}-05(0.9930)$ & $1.00259(0.0000)$ & $-0.607214(0.0000)$ & $-0.243807(0.0043)$ & 0.994688 & 0 \\
\hline $\mathrm{S} / \mathrm{M}$ & $0.003457(0.2265)$ & $0.904027(0.0000)$ & $-0.469059(0.0001)$ & $0.256234(0.0013)$ & 0.995678 & 0 \\
\hline $\mathrm{S} / \mathrm{L}$ & $-0.003498(0.0777)$ & $1.008951(0.0000)$ & $-0.709836(0.0000)$ & $0.243414(0.0001)$ & 0.998207 & 0 \\
\hline $\mathrm{B} / \mathrm{L}$ & $0.001544(0.6813)$ & $0.988465(0.0000)$ & $0.429367(0.0009)$ & $0.805964(0.0000)$ & 0.991917 & 0 \\
\hline $\mathrm{B} / \mathrm{M}$ & $0.001134(0.8084)$ & $0.913938(0.0000)$ & $0.374252(0.0073)$ & $0.160643(0.1140)$ & 0.987435 & 0 \\
\hline $\mathrm{B} / \mathrm{H}$ & $-0.002012(0.3082)$ & $0.997522(0.0000)$ & $0.33418(0.0000)$ & $-0.700114(0.0000)$ & 0.997934 & 0 \\
\hline
\end{tabular}

From the above regression analysis results, we can see that most of the P values of RM RF, SMB and HML in t-test are less than 0.05 , which indicates that these three factors are significant explanatory variables (Table $2 \& 3$ ). Therefore, it can be considered that in addition to market risk factors, there are scale factor (SMB) and book to market factor (HML) in China's stock market, which confirms that the Fama-French Three Factor Model is in line with Chinese stock market.

Compared with CAPM, the determinable coefficient $\mathrm{R}^{\wedge} 2$ of the Fama-French Three Factor Model is almost 0.99 , which is significantly higher than that of CAPM, 0.83. It shows that the fitting degree of the Fama-French Three Factor Model is very good, and the Three Factor Model can explain the risk return of China's SSE A-share better than CAPM.

\section{Conclusion}

The Three Factor Model improves the CAPM and makes it more general and widely applied to evaluate rate of return in stock market. The Three Factor Model improves and strengthens the explanatory power of CAPM by using $\beta$ coefficient and adding new factors at the same time. The Three Factor Model has fully considered the influence of company scale and $\mathrm{P} / \mathrm{B}$ ratio on its return rate. In the empirical analysis, Fama-French Three Factor Model can get a more accurate explanation.

In terms of the test results, both of two models can get a more explanatory prediction. But through the Three Factor Model, we can get more useful conclusions. After the financial crisis, risk control has become more important. Therefore, we are more eager to get a perfect model. When using the Three Factor Model, we find that: first, the return of value stock is higher than that of growth stock, because in our data, the average HML is greater than zero. Secondly, the return of small-scale companies is higher than that of large-scale companies, which is also confirmed by the fact that SMB in our data is greater than zero. Meanwhile, $\beta$ coefficient is still an essential factor for us to forecast and evaluate the yield.

However, the Three Factor Model also has shortcomings. If stocks are grouped according to their recent return performance which refers to momentum stock, then HML and SMB cannot explain the average return of stock.

\section{References}

[1] Markowitz. Portfolio selection [J]. The Journal of Finance, 1952.

[2] Fama E, French K. Common risk factors in the returns on stocks and bonds[J]. Journal of Financial Economics,1993. 
[3] Fama EF, French KR. Multifactor explanations of asset pricing anomalies[J]. The Journal of Finance, 1996.

[4] Bodie Z, Kane A, Marcus AJ. Essentials of Investments [M]. Beijing: China Renmin University Press, 2010.

[5] Zhang ZX, Investments [M]. Shanghai: Fudan University Press, 2011.

[6] Guo DZ. Mathematical Finance: The Principle and Model of Asset Pricing [M]. Beijing: Tsinghua University Press, 2006.

[7] Jin YH, Liu L. An empirical study on CAPM of china's stock market [J]. Journal of Financial Research, 2001, (7).

[8] Chen XY, Zhang YT, Chen DH. Cross sectional multi factor analysis of expected stock returns; empirical evidence from China's stock market [J]. Journal of Financial Research, 2000.

[9] Guan L. Comparing the price forecasting function of asset pricing models based on linear regression -- CAPM, FamaFrench Three Factor Model and its extended model [J]. Contemporary Economics, 2009, (9): 150-152.

[10] Du XQ, Nie ZP. Medium and long-term momentum effect and reversal effect in China's capital market: a further study based on Fama-French Three Factor Model [J]. Journal of Shanxi University of Finance and Economics, 2007, (12): 16-23.

[11] Qin Q. Test of CAPM on Shanghai stock market [J]. Journal of Hubei University of Economics (Humanities and Social Sciences), 2009, (7): 53-54.
[12] Zou XN, Hu CM. Empirical analysis of CAPM on China's listed coal stocks [J]. Finance \& Economy, 2009, (18): 58-59.

[13] Hu CM, Zou XN. An empirical analysis of the Shanghai Stock Exchange's Hunan block by CAPM [J]. Economic Vision (Part 2), 2009, (09): 32-33.

[14] Xia Y. On the validity test and improvement of CAPM in Shanghai Stock Exchange [J]. Modern Business Trade Industry, 2009, (11): 149-150.

[15] Li B, Wu SN. An empirical study on the effectiveness and applicability of CAPM -- a test of Shanghai stock market [J]. China Economic Studies, 2003, (02).

[16] Yu RY. The Enlightenment of Capital Asset Pricing Model (CAPM) on China's stock market [J]. Finance \& Economy, 2009, (20).

[17] Lin SG, Li CL. Concise Economic Statistics and Econometrics [M]. Shanghai: Shanghai People's Publishing House, 1996.

[18] Yang CJ, Xing J. CAPM empirical test of Shanghai stock market [J]. Journal of Shanghai Jiaotong University, 1998.

[19] Ruan T. Test of CAPM on Shanghai stock market [J]. Journal of Applied Statistics and Management, 2000.

[20] Shi DH. Empirical study on the risk of Shanghai stock market [J]. Economic Research Journal, 1996 (10). 